\title{
The Relationship Between Parents' Demographic Factors and Parenting Styles: Effects on Children's Psychological
}

\section{Adjustment*}

\author{
Demetris Hadjicharalambous, Loucia Dimitriou \\ Frederick University, Nicosia and Limassol, Cyprus
}

\begin{abstract}
The present study explored the extent to which parent's demographic characteristics, such as age, gender, education, place of residence, and family income have an influence on the parental style they adopt and consequently on their perception of their children's psychological adjustment in regards to their family relationships, peer relationships, school performance, and the development of their self-esteem. Various studies conducted in the past as well as in recent years indicate that parental demographic characteristics are significantly linked with parenting behavior (parental styles) and predict the way parents perceive their children's adjustment, development, and school achievement. The present study was quantitative and we applied three different self-report questionnaires, namely, a Personal Information Form (PIF) for the demographic data, the Parental Authority Styles (PAQ) Questionnaire, and the Questionnaire of Children's Family Relations, School Performance, Social Competence, and Self-Esteem. We administered the instruments to 336 Cypriot parents (23\% fathers and $77 \%$ mothers). Our results showed that parent's demographics are significantly related to the parenting styles they adopt. Furthermore, authoritative parenting is significantly correlated with positive parental perceptions of children' school performance, family relationships, social skills, and self-esteem. On the contrary, authoritarian parenting is a significant negative predictor to parental perceptions of children's adjustment in the aforementioned areas of development.
\end{abstract}

Keywords: authoritarian, authoritative, children adjustment, parenting styles, permissive

\section{Introduction}

The family, as one of the main institutions for children's socialization, is crucial in the development of their behaviour and personality. Negative parenting practices, experiences of domestic violence, parental conflicts, lack of care, neglect, demotion, overprotection, lack of tenderness and love, can have adverse effects and may lead to adopt children anti-social attitudes, which they seem to maintain both in the school environment as well as later in their adult life (Eysenck, 2013).

Within the family, we often find non-methodical but conscious mechanisms that act as catalysts to children's personality development. These might be the parental employment status, the family's

\footnotetext{
* Acknowledgements: The authors are grateful to the parents who participated in the research.

Demetris Hadjicharalambous, Dr., Lecturer, Psychology and Social Sciences Department, Frederick University, Nicosia and Limassol, Cyprus.

Loucia Dimitriou, Dr., Associate Professor, Psychology and Social Sciences Department, Frederick University, Nicosia and Limassol, Cyprus.
} 
socio-economic status and income, or parental expectations (Nova-Kaltsouni, 1995). According to Bloomfield and Kendall (2012) as well as Stewart-Brown (2008), parental behaviour plays a key role in children's emotional, social, and cognitive development and it is a critical factor to the development of children's mental health, delinquent behaviour, and academic success. Research data reveal that some of the key factors in the development of children's behavioural problems appear to be the absence of siblings, the small size and/or single-parent family, or parental conflict (Bayer, Hiscock, Ukoumunne, Price, \& Wake, 2008; Bayer, Sanson, \& Hemphill, 2006; Gustafsson et al., 2014; Heinrichs, Cronrath, Degen, \& Snyder, 2010). Pappa (2006) stated that children are influenced by who their parents are, i.e., their gender, origin, age, nationality, intelligence, education even their knowledge on child development.

The purpose of our research is to explore the extent to which parental demographic characteristics influence their parental style and the ways in which parents perceive their children's psychological adjustment. In this context, we postulated that:

1. Parental age, gender, level of education, place of residence, and family income all impact, to a greater or a lesser extent, the parenting styles they adopt.

2. Parental age, gender, level of education, place of residence, and family income all impact, to a greater or a lesser extent, the parents' perceptions of their children's psychological adjustment in family relations, school performance, social competence, and self-esteem.

3. Parenting styles influence the parents' perceptions of their children's psychological adjustment in family relations, school performance, social competence, and self-esteem.

\section{Parenting Styles}

Parental styles are defined as a set of parent's attitudes and behaviours towards their children. In terms of socialization, child development is based on processes that the parents consider most effective for their offspring's upbringing. Parental style reflects, amongst other things, parental attitudes, verbal and non-verbal expressions that characterize the nature of interactions within the family and the quality of communication between parent and child in various situations (Darling \& Steinberg, 1993; Pappa, 2006).

According to Baumrind's (1967) definition of parental styles, parents may be classified into specific categories. Each category identifies a specific type of parental behaviour and role within the family, as the father and the mother develop individually. Baumrind (1991) stated that the parental style, as perceived and evaluated by children, is defined by two basic dimensions: the dimension of demandingness and the dimension of emotional responsiveness. The dimension of demandingness refers to parents' high expectations and emotional distance from their children. The second dimension, emotional responsiveness, refers to parents' care or affection, i.e., the extent to which parents express emotional warmth in their relationship with their children, the ways in which they satisfy children's needs, and the degree to which they accept them and are involved in their lives (Maccoby \& Martin, 1983).

Baumrind's (1978) research revealed three main parental styles (types), according to parents' attitudes towards their children and the way they use their "power" to discipline them. These are authoritative, authoritarian, and permissive parenting. Maccoby and Martin (1983) later suggested a fourth parental style, namely, the uninvolved parenting. 


\section{Authoritative Parenting}

The authoritative parenting style is characterized by high levels of demandingness and care. Parents are involved in their children's lives and they participate in decisions that concern them. The quality of communication between children and parents is high and there is mutual acceptance and trust. Parents encourage children's psychological autonomy while monitoring their behaviour, and they want to know about and to take part in their children's activities. Authoritative parents explain to their children family rules; they give feedback and encourage the expression of children's objections (Vlachogianni \& Aggeli, 2014).

Authoritative parents encourage their children to be independent, although they do set boundaries and they are demanding, depending on the child's age and characteristics. They interact verbally with their children through discussion, they are warm and affectionate, and they use reasoning to achieve their goals (Dreikurs, 1991). At the same time, they recognize and respect the fact that their children have special interests and needs, which are essential elements for the well-functioning of their family (Buri, Louiselle, Misukanis, \& Mueller, 1989). According to Pappa (2006), authoritative parents do not use punishment, they rather follow guiding methods, which require more time but also improve the quality of the parent-child relationship. This proves to be particularly useful during adolescence, where the parent-child relationship is tested and communication is often disrupted.

Children of authoritative parents are characterized by emotional stability and satisfaction, self-confidence, self-control, and perseverance in completing an activity. According to Bezeveggis (2012), children of accepting and democratic parents are friendly and cooperative with good interpersonal relationships, high self-esteem, and self-confidence. Consequently, they adjust well and exceed in school (Radziszewska, Richardson, Dent, \& Flay, 1996) as they are also strongly motivated to succeed (Ginsburg \& Bronstein, 1993). Most research findings agree that children of authoritative parents encounter less behavioural issues and are frequently found to be more emotionally stable when compared to those raised by authoritarian or permissive parents (Dimitriou, 2001).

\section{Authoritarian Parenting}

Authoritarian parents are characterized by a high level of demandingness and a low level of care and response (Belsky, Crnic, \& Gable, 1995). It seems that authoritarian parents control their children's behaviour with strictness and punishment, and apply firm boundaries and rules, without negotiating with them or encouraging them to express their opinion. According to Chourdaki (1992), authoritarian parents use punishment to enforce, educate, and set an example for their children. Such punishments are reprimands, threats, and even physical punishment, which parents implement as warnings when children misbehave. In Pappa's (2006) view, authoritarian parents engage in very poor verbal interactions with their children. Furthermore, they push their children toward excellence in academic matters while they implement comparison with siblings and peers as motivation for success.

Research findings show that such practices limit children's development of autonomy and initiative, and have adverse effects on the emotional and psychological climate within the family. Children feel that their parents do not trust them, while, at the same time, parental overprotection causes children's' psychological suffocation (Cole \& Cole, 2002).

Parents who tend more toward authoritarian methods report that their children have lower social skills, reduced school competence and do not seem to rely on their own strengths, while they also develop problematic 
behaviour patterns (Hadjicharalambous \& Demetriou, 2020).

Chourdaki (1992) and Pappa (2006) claimed that often children of authoritarian parents are not happy or satisfied with themselves; they find it difficult to show initiative and to commit to goals, and therefore become easily frustrated and give up easily. Moreover, they tend more towards introversion and low self-esteem; they face issues of fear(s) and mistrust, while they battle aggressive behaviours when under pressure. At the core of the matter lays the fact that they are unconvinced of their parents' love and acceptance. Children of authoritarian parents are less active and less spontaneous, while their issues of mistrust make it difficult for them to create and maintain relationships with peers or to partake in social groups (Dimitriou, 2001).

\section{Permissive Parenting}

Permissive parents are gentle and indulgent when their children make mistakes and they forgive them easily. They try to show understanding towards misbehaviour and apply more communication, reasoning and explanation of family rules rather than punishments (Canitz, 1980). Due to their inability to set boundaries as well as their inconsistency to follow discipline, permissive parents exercise low control and have few demands for mature behaviour by their children (Dimitriou, 2001; Pappa, 2006). According to Pappa (2006), permissive parents encourage their children to self-regulate their behaviour rather than to just follow rules.

Children of permissive parents are likely to adopt egocentric behaviour patterns. Their lack of impulse control, their limited respect towards others as well as their inability to follow rules all have a negative impact when it comes to peer relations and interactions (Vlachogianni \& Aggeli, 2014). According to Baumrind (1991), the fact that they tend to be more "takers" rather than "givers" as well as their lack of solidarity and compassion makes their interrelations with others quite difficult. This often results in more impulsive and sometimes even aggressive behaviours (Dimitriou, 2001). Other behavioral issues manifest in immature behavior patterns, lack of responsibility as well as over-dependency on adults (Maccoby \& Martin, 1983).

Extensive research on Baumrind's parenting styles shows that children of authoritarian parents, who exercise high control, and children of permissive parents who use low or no control at all tend more towards emotional and behavioural problems in comparison with children of authoritative parents (Baumrind, 1991; Bigner, 1994; Forward, 1989; Maccoby \& Martin, 1983; Sang, Daniels, \& Kissinger, 2006; Whitfield, 1987).

\section{Uninvolved Parenting}

The lack of involvement and support of uninvolved parents manifests in their low level of care and their high level of tolerance. Uninvolved parents display a lack of demands, support, and encouragement toward their children. This type of parents does not get involved in or monitor their children's activities (Georgiou, 2005; Pappa, 2006). In fact, they seem so busy with their own activities that they fail to actually take care of their children, to the extent that their behaviour can be characterized as neglecting and abusive (Bezeveggis, 2012). While they often provide food, clothing, and accommodation, uninvolved parents fail to provide the necessary organizing, disciplining, activating, monitoring, and supervising of their children and their activities (Pappa, 2006). Furthermore, they show little interest in their children's learning experiences at school or their after-school ventures. As Pappa (2006) claimed, such parents usually maintain the immaturity and egocentrism of their own childhood, probably because they also had similar dissatisfying experiences while growing up. Their dissatisfaction carries over into their adulthood, and is manifested in their inadequacy in their parental role as well as their lack of interest in the development of their children (Vander, 1993).

Children of uninvolved parents tend to be antisocial, and are characterized by internalization and 
externalization problems (Pappa, 2006). Their lack of maturity and motivation leads to low school performance, which in turn creates more difficulties in developing their confidence and self-esteem. During adolescence, children of uninvolved parents develop and display negative attitudes toward their parents. Due to the neglect they experience, these children often show a lack of self-control and are more at risk than others for adopting delinquent behavioural patterns (Georgiou, 2002).

\section{Method}

\section{Sample}

The study took place in the city of Limassol in Cyprus, in the fall of 2019. Specifically, our sample consisted of parents who lived in the Western suburbs of Limassol (Polemidia and Ipsonas) which are populated by approximately 35,000 people. Our participants were 336 Greek speaking parents who had children in the public primary school. The majority of the participating parents were mothers $(77 \%)$ and most had one or two children. Regarding the sample's marital status, residence, family income, and educational level, our data analysis indicated that the majority of the participants was married (74\%) and resided in urban areas (70.2\%). Most of the parents of our sample had a secondary school education, whereas $62.2 \%$ of them reported that they had a monthly income in the range of 1,500-3,000 Euros.

\section{Procedure-Data Collection}

Data collection was conducted through face-to-face meetings held with groups of parents at the children's local public elementary school(s). The participants were informed about the research before they were asked to complete the questionnaires. The research team explained the Likert rating scales of the questionnaires and emphasized that they were to answer all the questions with reference to their child who was a pupil (6-12 years old) at the same school. The researchers collaborated with and collected data from parents from 10 different public elementary schools in the municipalities of Ipsonas and Polemidia. Parents completed the Personal Information Form (PIF), the Parental Authority Styles (PAQ) Questionnaire, and the Questionnaire of Children's Family Relations, School Performance, Social Competence, and Self-Esteem.

\section{Instruments}

The PIF was used to collect demographic data information regarding the parent's age, gender, marital status, residence, family income, educational level, number of children, and children's age and gender. The Personal Information Form consisted of nine questions. The second questionnaire was Buri's (1991) Parenting Authority Styles Questionnaire and the third instrument was Kontopoulou's (2008) questionnaire in which parents report on their children's family relations, school performance, social competence, and self-esteem. We applied all instruments in their Greek language versions.

Buri's (1991) Parenting Authority Styles Questionnaire aims to explore parental styles that parents apply to their children's education and rearing and includes 30 questions. The questionnaire loads to three factors. The first factor is "authoritarian parenting" and refers to the parents' strictness and rigidity in the socialization methods they apply with their children. The second factor refers to "authoritative parenting" where it is argued that parents have a more democratic approach towards their children through dialogue, discussion, and joint parent-child decisions. The third factor refers to "permissive parenting" which states that parents have a relaxed approach towards their children and hardly set limits.

The questionnaire of family relations, school performance, social competence, and self-esteem for children 
(Kontopoulou, 2008) explores parent's perceptions for the developmental characteristics of their child (7-12 years old). It includes 31 items that record the children's overall self-esteem scale as perceived by their parents. The questionnaire loads at three factors: The first factor is family competences and refers to the satisfaction that the child receives from family relationships; the second factor is social competences and addresses one's relationships with peers; and the third factor is school competences and refers to assessing the children's performance and adaptation to school. The sum of all factors indicates the score of children's self-esteem.

\section{Data Analysis}

Data analysis was conducted with the use of the Statistical Package for Social Sciences (SPSS) version 25.0. We summarized and analyzed our data through descriptive statistics, such as mean, standard deviation, frequencies, and percentages to describe the participants' demographic characteristics. Distributions of frequencies and percentages were calculated in order to analyze data obtained from the parents' personal information form.

To examine our three research hypotheses, namely, that: (1) Parental age, gender, level of education and family income all impact, to a greater or a lesser extent, the parenting styles they adopt; (2) parental age, gender, level of education and family income all impact, to a greater or a lesser extent, the parents' perceptions of their children's psychological adjustment in family relations, school performance, social competence and self-esteem; and (3) parenting styles influence the parents' perceptions of their children's psychological adjustment in family relations, school performance, social competence and self-esteem we implemented the following data analysis methods: The two-way ANOVA and multivariate ANOVA (MANOVA) to compare means between parental styles, parent's characteristics and the impact on parent's perceptions of their children's adjustment. Parental demographic characteristics (parent's age, gender, marital status, residence, family income, educational level, number of children, and children's age and gender) were used as independent variables to examine their influence on the parental style. Also, we applied the Pearson correlation coefficient to explore whether correlations (positive or negative) between parental styles and parents' perceptions of children's family relations, school performance, social competence and children' self-esteem were significant. Additionally, we applied a regression analysis to examine if parenting styles (authoritarian, authoritative, or permissive) can predict children's psychological adjustment.

\section{Descriptive Indicators and Internal Consistency Values (Reliability)}

Table 1 presents the descriptive indicators and the internal consistency values of the tools. The reliability of the Parenting Styles Questionnaire ranged from 0.82 to 0.85 . The "Authoritarian Parenting" factor had a reliability of 0.85 , the "Authoritative Parenting" factor of 0.82 , and the "Permissive Parenting" factor of 0.85.

Table 1

Descriptive Indicators and Values of Internal Consistency of Tools

\begin{tabular}{lll}
\hline Questionnaires & Authors & Our research \\
\hline Parenting Styles Questionnaire (Buri, 1991) & Cronbach alpha & Cronbach alpha \\
Authoritarian Parenting & 0.82 & 0.85 \\
Authoritative Parenting & 0.78 & 0.82 \\
Permissive Parenting & 0.85 & 0.85 \\
Questionnaire of family relations, school performance, social & Cronbach alpha & Cronbach alpha \\
competence and self-esteem for children (Kontopoulou, 2008) & 0.78 & 0.82 \\
Family Relations & & 0 \\
\hline
\end{tabular}




\begin{tabular}{lll}
\hline Social Competence & 0.75 & 0.79 \\
School Performance & 0.77 & 0.77 \\
Children's self-esteem & 0.85 & 0.88 \\
\hline
\end{tabular}

The reliability of the Questionnaire of Family Relations, School Performance, Social Competence, and Self-Esteem for Children ranges from 0.77 to 0.88 . The "Family Relations" factor has a reliability of 0.82 , the "Social Competence" factor has a reliability of 0.79, the "School Performance" factor has a reliability of 0.77 and the "Children's Self-Esteem" factor has a reliability of 0.88 . Data analysis shows that our results are in compliance with the reliability of the original scales.

\section{Results}

In examining our first hypothesis, we detected statistically significant relationships between all five parental demographic characteristics that we considered in our research, namely, gender, family income, place of residence, age, and level of education with the parenting styles that they adopt.

More specifically, the gender of the parents was found to be significant regarding the frequency in adopting an authoritarian parenting style $[\mathrm{F}(1,332)=97.24, p<0.001]$. When compared with the mothers, the fathers of our sample applied stricter methods of discipline towards their children. Not only parental gender but also family income was found to be statistically significant to authoritarian parenting $[\mathrm{F}(1,335)=3.42, p<0.05]$. Our findings showed that mothers with lower family income were more authoritarian than fathers with low income, but also in comparison to parents of both genders with higher family income.

Our findings also showed that the parent's place of residence (rural vs. urban) was significant for adopting both an authoritarian $[\mathrm{F}(1,335)=21.83, p<0.05]$ as well as an authoritative parenting style $[\mathrm{F}(1,335)=8.42, p$ $<0.00]$. Fathers who resided in rural areas appeared to be more authoritarian than mothers in rural areas but also than parents of both genders who lived in urban areas. Our research showed that mothers who lived in urban areas used more authoritative parenting methods towards their children when compared to parents who lived in rural areas and fathers who lived in urban areas. The parent's place of residence was also found to be statistically significant with the permissive parenting style $[\mathrm{F}(1,335)=21.44, p<0.05]$. Namely, parents residing in urban areas were more permissive $(\mathrm{M}=24.72, \mathrm{SD}=3.12)$ than parents who lived in rural areas have $(\mathrm{M}=23.64, \mathrm{SD}=3.56)$.

Further analysis of demographic data indicated that parental age also played a significant role as far as parental style is concerned. Our findings showed that older parents were significantly more authoritative towards their children than younger parents. Younger parents stated that their partners used more permissive parenting methods $(\mathrm{M}=23.89, \mathrm{SD}=3.24)$ than the partners of the older parents $(\mathrm{M}=25.02, \mathrm{SD}=3.26)$.

Moreover, the parental educational level was found statistically significant with the permissive parenting and with the authoritarian parenting style. $[\mathrm{F}(1,335)=22.13, p<0.05]$. Indeed, parents with secondary education adopted more frequently a permissive parenting style $(\mathrm{M}=24.85, \mathrm{SD}=3.24)$ than parents with higher education $(\mathrm{M}=23.00, \mathrm{SD}=3.08)$. At the same time, though parents with a secondary education appeared to be more authoritarian towards their children $(\mathrm{M}=28.16, \mathrm{SD}=2.61)$ than parents with higher education $(\mathrm{M}=27.45, \mathrm{SD}=3.01)$. Last but not least, the number of children in the family appeared to play a significant role in parents' adopting permissive and authoritative parenting styles $[\mathrm{F}(1,335)=28.87, p<0.05]$. Our findings showed that parents who had one or two children were more authoritative towards their children, than parents who had three children or more. 
Regarding our second hypothesis, data analysis revealed that three demographic characteristics, such as age, place of residence, and education had a significant impact on parent's perception of their child's psychological adjustment. Gender and family income played no significant role in parental perceptions of their child's psychological adjustment in family relations, school performance, social competence, and self-esteem.

Regarding parent's place of residence (rural vs. urban) participating parents who lived in urban areas regarded their child's family relations as better developed than parents residing in urban areas $[\mathrm{F}(1,335)=5.886$, $p<0.016]$. Moreover, parents residing in urban areas stated that their children had higher school performance, and social competences $[\mathrm{F}(1,335)=5.494, p<0.020]$ and higher self-esteem $[\mathrm{F}(1,335)=5.768, p<0.017]$ than the parents of children who are lived in rural areas.

Demographic data, such as parental age seemed to also affect significantly their perceptions regarding their children's psychological adjustment. Older parents stated that their children had higher school performance $(M=21.46, S D=6.51)$, more social competences $(M=19.51, S D=8.15)$, and higher self-esteem $(\mathrm{M}=24.61, \mathrm{SD}=8.02)$ in comparison to parents of a younger age. The parental level of education was also found to play a significant role in the way that parents assessed their child's school performance. Our findings showed that parents with a higher education stated that their children had higher school performance $(\mathrm{M}=$ $22.47, \mathrm{SD}=7.02)$ than the parents with secondary education $(\mathrm{M}=14.49, \mathrm{SD}=4.93)$.

In regards to examining our third hypothesis, we applied a correlation analysis between the variables "Parental Style" and "Children's Psychological Adjustment". Our findings indicated that where parents applied authoritarian methods their perception of their children's psychological adjustment tended to be negative. On the other hand, authoritative parents viewed their children's family relations, school performance, social competences, and self-esteem in a positive way.

Our analysis indicated a significant negative correlation between the authoritarian parental style and parental perceptions of their child's family relations $(r=-0.217, p<0.000)$, school performance $(r=0.286, p<$ $0.000)$, social competences $(r=-0.198, p<0.000)$, and children's self-esteem $(r=-0.245, p<0.000)$. In effect, when parents employed stricter disciplining methods and control then they perceived their children as less competent in the competences mentioned above.

On the other hand, the authoritative parental style showed a significant positive correlation with parent's perceptions of their child's family relations $(r=0.780, p<0.000)$, as well as with school performance $(r=$ $0.678, p<0.000)$, with social competence $(r=0.540, p<0.000)$, and with children's self-esteem $(r=0.899, p$ $<0.000$ ). These findings indicate that parents who employed democratic child-rearing methods also tended to perceive their children's psychological adjustment in a positive way. No similar correlation was detected for parents who adopted a permissive parental style $(r=0.016, p<0.769)$. However, our data showed that parents who raised their children with a permissive style tended to also evaluate positively their school performance $(r$ $=0.154, p<0.000)$, their social competence $(r=0.230, p<0.000)$, and their self-esteem $(r=0.199, p<0.000)$. On the other hand, when participating parents applied more permissive methods, then they stated that their child derived less satisfaction from family relationships $(r=-0.187, p<0.000)$.

Interestingly enough, when parents stated that their child enjoyed good family relations then they also claimed that he/she had a better school performance $(r=0.884, p<0.000)$ and social competences $(r=0.872, p$ $<0.000)$ as well as a high self-esteem $(r=0.954, p<0.000)$. We detected the same tendency regarding school performance. Indeed, when parents evaluated their child's school performance as positive, then they also stated that their child had higher social competence $(r=0.871, p<0.000)$ and higher self-esteem $(r=0.961, p<$ 
0.000). Our findings also indicated a statistically significant positive correlation between parental perception of social competences and children's self-esteem $(r=0.957, p<0.000)$ (see Table 2).

Table 2

Correlation Between Parenting Style and Family Relations, School Performance, Social Competence, Children's Self-Esteem

\begin{tabular}{llllllll}
\hline Pearson $r$ & \multirow{2}{*}{ Authoritarian } & \multirow{2}{*}{ Authoritative } & \multirow{2}{*}{ Permissive } & $\begin{array}{l}\text { Family } \\
\text { Relations }\end{array}$ & $\begin{array}{l}\text { School } \\
\text { Performance }\end{array}$ & $\begin{array}{l}\text { Social } \\
\text { Competence }\end{array}$ & $\begin{array}{l}\text { children's } \\
\text { self-esteem }\end{array}$ \\
\hline Authoritarian & 1 & 0.052 & 0.069 & $-0.217^{*}$ & $-0.286^{*}$ & $-0.198^{*}$ & $-0.245^{*}$ \\
Authoritative & & 1 & 0.016 & $0.780^{*}$ & $0.678^{*}$ & $0.540^{*}$ & $0.899^{*}$ \\
Permissive & & 1 & $-0.187^{*}$ & $0.154^{*}$ & $0.230^{*}$ & $0.199^{*}$ \\
Family Relations & & & 1 & $0.884^{*}$ & $0.872^{*}$ & $0.954^{*}$ \\
School Performance & & & & 1 & $0.871^{*}$ & $0.961^{*}$ \\
$\begin{array}{l}\text { Social Competence } \\
\text { children's Self-Esteem }\end{array}$ & & & & & 1 & $0.957^{*}$ \\
\hline
\end{tabular}

Note. ${ }^{*} p<0.05$.

The regression analysis we applied in order to examine whether parenting styles (authoritarian, authoritative, and permissive) could predict children's psychological adjustment was statistically significant $\mathrm{F}(10,325)=88.098, p<0.000$, thus interpreting $73 \%$ of the total variance $\left(r^{2}=0.731\right.$, Adjusted $\left.r^{2}=0.722\right)$. "Authoritative Parenting" $(\beta=0.095, p<0.05)$ was found to be a positive predictor for "Family Relations", thus indicating that when parents adopted an authoritative parental style, they also perceived that their children gained more satisfaction from interactions in the family. On the other hand, "Authoritarian Parenting" ( $\beta=$ -0.157, $p<0.028$ ) was found to be a negative predictor for "Family Relations", i.e., when parents used strictness and punishment then they reported that their children derived less satisfaction from their family relations. "Permissive Parenting" was not a significant predictor for "Family Relations".

Further analysis showed that "Authoritative Parenting" $(\beta=0.109, p<0.01)$ could also be a positive predictor for children's "School Performance". Both "Authoritarian Parenting" $(\beta=-0.589, p<0.000)$ and "Permissive Parenting" ( $\beta=-0.273, p<0.000)$ were found to be negative predictors of children's "School Performance". In the same framework "Authoritative Parenting" $(\beta=0.638, p<0.000)$ could also predict positively children's "Social Performance" whereas "Authoritarian Parenting" $(\beta=-0.693, p<0.000)$ was found to be a negative predictor for parental perception of their children's relationships with their peers. "Permissive Parenting" was not a statistically significant predictor of parent's assessment of their children's "Social Competence".

Finally, our findings showed that parents that adopted either "Authoritative Parenting" $(\beta=1.789, p<$ $0.000)$ or "Permissive Parenting" ( $\beta=0.506, p<0.05)$, also perceived their children's self-esteem as elevated. Alternatively, those who adopted "Authoritarian Parenting" strategies $(\beta=-1.942, p<0.000)$ assessed the self-esteem of their children as low.

\section{Discussion}

The findings of the present study confirm to a great extent our three hypotheses. Indeed, all five parental demographic characteristics that we considered in our research, namely, gender, family income, place of residence, age, and level of education were found to be significant determinants of parental styles and socialization practices. Regarding our second hypothesis, data analysis revealed that three demographic 
characteristics, i.e., age, place of residence, and education had a significant impact on parent's perception of their child's psychological adjustment. Last but not least, our findings indicated that where parents applied authoritarian child-rearing methods their perception of their children's psychological adjustment tended to be negative. On the other hand, authoritative parents viewed their children's family relations school performance, social competences and self-esteem in a positive way.

Gender was found to be a significant determinant of the parental style that fathers and mothers adopt, whereas our participating mothers used more authoritative methods of socialization and fathers applied more authoritarian parenting practices. Furthermore, regarding the mother's educational level and the parental style that she adopts, Coleman and Karraker (2000) stated that a mother's high level of education improves a child's cultural development. Their research showed that educated mothers seemed to have a wider range of knowledge about children's development and they applied more effective parenting practices and strategies, thus achieving better interaction with their children. Furthermore, their results indicated that a family's higher income allowed mothers to provide their children with the opportunity to participate in activities that promoted children's spiritual and emotional development. Leaper (2002) also claimed that parental gender had an effect on parenthood while Kyazze, Maani, and Lubaale's (2020) findings showed that mothers were more expressive and supportive in their relationship with their children than fathers, who seemed to be more demanding. According to Phares, Fields, and Kamboukos (2009), the parental style that mothers and fathers adopted was in relation to the gender roles that mothers and fathers adopted in society. In most societies, the mother is expected to spend more time than the father to provide care, affection, support, and warmth (McKinney \& Rend, 2008). In fact, findings by Uji, Sakamoto, Adachi, and Kitamura (2014) showed that mothers actually spent more time raising their children than fathers. According to Hudson, Elek, and Fleck (2001) and Lansford et al. (2011), fathers were more likely to feel that they failed in their parental role, as they perceived themselves as ineffective to nurture their children when they compared themselves to mothers. In fact, fathers frequently evaluated their ability to raise their children according to the financial security they could provide (Barret \& Robinson, 1990; Rhein et al., 1997). Mothers were more likely to feel the lack of ability to raise children when they experienced marital conflicts (Ryan, Tolani, \& Brooks-Gunn, 2009; Wayland \& Rawlins, 1997). According to Martinson, Holman, Larson, and Jackson (2010), mothers more often than not, did not apply harsh and punitive strategies to raise their children but rather adopted collaborative and child-centred approaches.

The family's socio-economic status is defined by the education of the parents, their professions and the family's income. In the present study, we were able to show a statistically significant difference between participating parents with lower education and those with a higher education regarding the parental style that they adopted. Indeed, parents with a lower education applied more authoritarian parental practices and, at the same time, they appeared to be more permissive toward their children. On the other hand, parents with a higher level of education reported that their children enjoyed better family relations, achieved higher school performance, and higher self-esteem than parents with lower education. Research findings of Bezeveggis (2012) showed that parents with a higher educational level tended to reinforce their children's behaviour more while they adopted a dialectical communication model with them. They praised their children for positive behaviours, they had good communication skills and they created an environment with cognitive stimuli that contributed to children's development.

Brewer (1991) showed that mothers of lower socioeconomic status were more satisfied in their parenting role. Let it be noted that mother's parental satisfaction may have been expressed due to several factors, i.e., 
having financial support or a enjoying the benefits of a supportive network of family and friends. At the same time, Brewer's results may have been influenced by the fact that all participating mothers had children under the age of five years, whereas younger children are often thought to be a source of satisfaction for most women. In compliance with Hoff-Ginsberg's (1998) findings, our results showed that mothers with lower family income were more authoritarian than fathers with low income, but also in comparison to parents of both genders with higher family income. Hoff-Ginsberg's (1998) research revealed that mothers with higher socioeconomic status spoke more to their children, and used more explanations and reasoning than mothers with lower socioeconomic status. Consequently, their children excelled in speech and vocabulary development. According to Hoff, Laursen, and Tardif (2002), parents with low socioeconomic status felt that they had less control over their children's behaviour than parents of high socio-economic status. Living conditions, such as neighbourhoods with crime, may in fact, cause parents to feel insecure and this may lead to the implementation of stricter parental practices. The way of parents to educate and raise their children differs significantly according to their socio-economic status, as, inevitably, they have different life experiences. Research also showed that parents with low socioeconomic status strived to raise their children, while parents of high socio-economic status prioritized the children's development towards independence. Parents with a high socio-economic status used disciplinary techniques, such as guilt and reasoning, while parents with a low socio-economic status tended to resort more frequently to corporal punishment (Strauss \& Stewart, 1999; Hoff et al., 2002).

Parents' perceptions, values, beliefs, and expectations are an important factor in the way they raise their children but also a significant factor in shaping children's behaviour. Parents' expectations for children's successful career paths are also linked to their active involvement (Grolnick, Benjet, Kurowski, \& Apostoleris, 1997). In the present study, three demographic characteristics, such as age, place of residence, and education had a significant impact on parent's perceptions of their child's psychological adjustment. Gender and family income played no significant role in parental perceptions of their child's psychological adjustment in family relations, school performance, social competence, and self-esteem.

According to our findings, demographic data, such as parental age affected significantly the parent's perceptions of their children's psychological adjustment. Older parents stated that their children had higher school performance more social competences, and higher self-esteem in comparison to parents of a younger age. Our findings seem to be in accordance with Bezeveggis's (2012) results, namely that older parents (aged 30-40) were more mature and were likely to satisfy more frequently their children's needs. Research also shows that mothers over 30 years old adapted well and were happier with their parental role. On the contrary, according to Cox, Paley, Payne, and Burchinal (1999) as well as Florsheim et al. (2003), adults who became parents at a young age experienced stress in their relationships. Young couples with low incomes, faced a number of challenges whereas particularly young mothers often had limited social support in raising their children than older mothers (Gonzalez, Jones, \& Parent, 2014). It is considered rather positive that nowadays, a majority of people prefer to pursue their education and have a steady employment before they decide to become parents, as according to Dimitriou (2001) people that have achieved their personal goals tend to experience more readiness to adapt to the responsibilities of the parental role.

Regarding the parent's place of residence (rural vs. urban) participating parents who lived in urban areas regarded their child's family relations as more positive than parents residing in rural areas. Moreover, parents residing in urban areas stated that their children had higher school performance, better social competences and higher self-esteem than the parents of children who lived in rural areas. In fact, Galani (2011) was able to show 
that parents who lived in urban areas were more supportive to their children than parents who lived in rural areas. Consequently, the children who lived in urban areas showed better family relations in comparison to children who lived in rural areas. Last but not least, the parental level of education was also found to play a significant role in the way that parents assessed their child's school performance. Our findings showed that parents with a higher education stated that their children had a better school performance than the parents with secondary education.

In the beginning of our research, we postulated that parenting styles influence the parents' perceptions of their children's psychological adjustment in family relations, school performance, social competence, and self-esteem. Indeed, our findings showed that when parents applied authoritarian methods their perception of their children's psychological adjustment tended to be negative. On the other hand, authoritative parents viewed their children's family relations school performance, social competences, and self-esteem in a positive way. If we were to reverse our perspective, we would, in fact, be able to see that in regards to parent-child relationships children's perspective on their parent's child-rearing style confirms our findings. Research by Demetriou and Christodoulides (2011) showed that $98 \%$ of the Greek Cypriot children assessed their parents as caring and accepting.

Our findings comply with research by Bloomfield and Kendall (2012), Stewart-Brown (2008), and Temiz, (2020) who also indicated that parental behaviour played a key role in children's emotional, social, cognitive development and academic success in both childhood and adulthood. Vlachogianni and Aggeli (2014) stated that communication between children and authoritative parents is enhanced as parents encourage children's psychological autonomy, explain the family's rules and give feedback. Hadjicharalambous and Demetriou (2020) stated that parents who implemented authoritative parenting practices perceived enhanced social skills, self-esteem, and family and school competence in their children.

Bezeveggis (2012) was also able to show that children of authoritative parents have improved social skills. They are friendly, cooperative, and maintain good interpersonal relationships. Research findings showed that these children functioned well socially were friendly with their peers and had a strong achievement motivation (Ginsburg \& Bronstein, 1993; Baumrind, 1991; Dimitriou, 2001). According to Pappa (2006), children of authoritarian parents tended to be are unhappy with themselves, dissatisfied, had no goals, gave-up easily, and became frustrated quickly. Dimitriou (2001) also stated that children of authoritarian parents tended to be less active and spontaneous, while, at the same time, they encountered difficulties in their interpersonal relationships with peers. Furthermore, children of permissive parents were more likely to show problematic behaviour and were less likely to succeed in school. These children tended to be egocentric, impulsive, and disobedient, had low self-control and a reduced ability to handle stress. Pappa (2006) was able to show that children of uninvolved parents were antisocial, characterized by internalization and externalization problems. They had a low tolerance to rules and boundaries and developed a significantly negative attitude toward their parents.

\section{Conclusion}

Differences between children in regard to their psychological adjustment are related to specific strategies which parents implement in the socialization process. Our results confirmed our three hypotheses indicating that parental style is significantly influenced by gender, family income, and place of residence, age and level of education. Parental perception of children's school performance, peer relations, and self-esteem is also largely 
predicted by demographic factors, such as age, place of residence (urban vs. rural), and level of education. Last but not least, our findings confirmed that authoritative parents tended to assess their children's family relations school performance, social competences, and self-esteem in a positive way.

Future studies on parental styles would benefit from researching the role of more factors, which may predict children's psychological adjustment and family functioning, such as parental stress levels and the quality of their marital relationship. Such or similar research findings could guide practitioners on where to focus more in order to make parenting programmes more effective.

\section{References}

Barret, R. L., \& Robinson, B. E. (1990). The role of adolescent fathers in parenting and childrearing. Advances in Adolescent Mental Health, 4, 189-200.

Baumrind, D. (1967). Effects of authoritative parental control on child behaviour. Child Development, 37(4), 887-907.

Baumrind, D. (1978). Parental disciplinary patterns and social competence in children. Youth and Society, 9(3), 239-276.

Baumrind, D. (1991). The influence of parenting style on adolescent competence and substance use. Journal of Early Adolescence, $11(1), 56-95$.

Bayer, J. K., Hiscock, H., Ukoumunne, O. C., Price, A., \& Wake, M. (2008). Early childhood aetiology of mental health problems: A longitudinal population-based study. Journal of Child Psychology and Psychiatry and Allied Disciplines, 49(11), 1166-1174.

Bayer, J. K., Sanson, A. V., \& Hemphill, S. A. (2006). Parent influences on early childhood internalizing difficulties. Journal of Applied Developmental Psychology, 27(6), 542-559.

Belsky, J., Crnic, K., \& Gable, S. (1995). The determinants of co-parenting in families with toddler boys: Spousal differences and daily hassles. Child Development, 66(3), 629-642.

Bezeveggis, H. (2012). Family and child. Retrieved from http://blogs.sch.gr/kiourtsis/files/2012/10/8_meros.pdf

Bigner, J. J. (1994). Individual and family development: A life-span interdisciplinary approach. New Jersey: Prentice Hall.

Bloomfield, L., \& Kendall, S. (2012). Parenting self-efficacy, parenting stress and child behaviour before and after a parenting programme. Primary Health Care Research \& Development, 13(4), 364-372.

Brewer, B. M. (1991). The social self: On being the same and different at the same time. Personality and Social Psychology Bulletin, 17(5), 475-482.

Buri, J. R. (1991). Parental authority questionnaire. Journal of Personality Assessment, 57(1), 110-119.

Buri, J., Louiselle, P., Misukanis, T., \& Mueller, R. (1989). Effects of parental authoritarianism and authoritativeness on self-esteem. Personality and Social Psychology Bulletin, 14, 271-282.

Canitz, H. (1980). Father: Man, new role into the family. Athens: Notos Publishing.

Carlo, G., White, R. M., Streit, C., Knight, G. P., \& Zeiders, K. H. (2018). Longitudinal relations among parenting styles, prosocial behaviors, and academic outcomes in US Mexican adolescents. Child Development, 89(2), 577-592.

Chourdaki, M. (1992). Family psychology. Athens: Gregori Publishing.

Cole, M., \& Cole, S. R. (2002). Child development: Cognitive and psychosocial development in infancy and middle childhood (Volume B). Athens: Tupothito.

Coleman, P. K., \& Karraker, K. H. (2000). Parenting self-efficacy among mothers of school-age children: Conceptualization, measurement, and correlates. Family Relations, 49(1), 13-24.

Cox, M. J., Paley, B., Payne, C., \& Burchinal, M. (1999). The transition to parenthood: Marital conflict and withdrawal and parent-infant interactions. In M. Cox and J. Brooks-Gunn (Eds.), Conflict and cohesion in families (pp. 87-104). Mahwah, NJ: Laurence Erlbaum Associates.

Darling, N., \& Steinberg, L. (1993). Parenting style aw context: An integrative model. Psychological Bulletin, 113(3), 487-496.

Demetriou, L., \& Christodoulides, P. (2011). Personality and psychological adjustment of the Greek-Cypriot youth in the context of the Parental Acceptance-Rejection Theory. The Cyprus Review, 23(1), 81-97.

Dimitriou, L. (2001). The first 6 years of child's life. Athens: Pedio.

Dreikurs, R. (1991). The challenge to be parents. Athens: Glaros Publishing.

Eysenck, M. W. (2013). The impact of parental psychological difficulties on their children. In A. S. Antoniou and B. D. Kirkcaldy (Eds.), Education, family and child and adolescent health (pp. 21-35). Athens: Diadrassi. 
Florsheim, P., Sumida, E., McCann, C., Winstanley, M., Fukui, R., Seefeldt, T., \& Moore, D. (2003). The transition to parenthood among young African American and Latino couples: Relational predictors of risk for parental dysfunction. Journal of Family Psychology, 17(1), 65-79.

Forward, S. (1989). Toxic parents: Overcoming their hurtful legacy and reclaiming your life. New York: Bantam Books.

Galani, A. X. (2011). The effect of the characteristics of the large and non-large family on the psychosocial development of children and adolescents (Master thesis, Ioannina University, Greece).

Georgiou, S. (2002). Family-school relationship, child's development. Athens: Ellinika Grammata.

Georgiou, S. (2005). Education: Lifespan. Athens: Kastanioti.

Ginsburg, G., \& Bronstein, P. (1993). Family factors related to children's intrinsic/extrinsic motivational orientation and academic performance. Child Development, 64(5), 1461-1474.

Gonzalez, M., Jones, D., \& Parent, J. (2014). Co-parenting experiences in African American families: An examination of single mothers and their nonmarital co-parents. Family Process, 53(1), 33-54.

Grolnick, W., Benjet, C., Kurowski, C., \& Apostoleris, N. (1997). Predictors of parent involvement in children's schooling. Journal of Educational Psychology, 89(3), 538-548.

Gustafsson, H. C., Barnett, M. A., Towe-Goodman, N. R., Mills-Koonce, W. R., Cox, M. J., \& Family Life Project Key Investigators. (2014). Family violence and children's behaviour problems: Independent contributions of intimate partner and child-directed physical aggression. Journal of Family Violence, 29(7), 773-781.

Hadjicharalambous, D., \& Demetriou, L. (2020). The quality of the parent-child relationship and children's family, school and social competences in Cyprus. International Journal of Social Sciences Perspectives, 7(1), 22-33.

Heinrichs, N., Cronrath, A. L., Degen, M., \& Snyder, D. K. (2010). The link between child emotional and behavioural problems and couple functioning. Family Science, 1(3-4), 152-172.

Hoff-Ginsberg, E. (1998). The relation of birth order and socioeconomic status to children's language experience and language development. Applied Psycholinguistics, 19(4), 603-630.

Hoff, E., Laursen, B., \& Tardif, T. (2002). Socioeconomic status and parenting. In Bornstein, M. H. (ed.), Handbook of Parenting: Second Addition, Erlbaum, Mahwah, NJ.

Hudson, D. B., Elek, S. M., \& Fleck, C. M. (2001). First-time mothers' and fathers' transition to parenthood: Infant care self-efficacy, parenting satisfaction, and infant sex. Issues in Comprehensive Pediatric Nursing, 24(1), 31-43.

Kontopoulou, M. (2008). Psychosocial criterion of school social competence. In The context of EPEAEK project psychometric-Differential evaluation of children and adolescents with learning difficulties (pp. 1-54). Greece Thessaloniki Aristotle University.

Kyazze, D. R., Maani, J. S., \& Lubaale, G. (2020). Fathers' parenting practices and the children's approaches to learning from three through five years: A case of Mityana District, Uganda. Psychology, 10(2), 57-64.

Lansford, J. E., Bornstein, M. H., Dodge, K. A., Skinner, A. T., Putnick, D. L., \& Deater-Deckard, K. (2011). Attributions and attitudes of mothers and fathers in the United States. Parenting: Science and Practice, 11(2-3), 199-213.

Leaper, C. (2002). Parenting boys and girls. In M. H. Bornstein (Ed.), Handbook of parenting, Vol. 2: Biology and ecology of parenting. Mahwah: Lawrence Erlbaum Associates Publishers.

Maccoby, E., \& Martin, J. (1983). Socialization in the context of the family: Parent-child interaction. In P. Mussen (Ed.), Handbook of child psychology (Vol. 4). New York: Wiley.

Martinson, V. K., Holman, T. B., Larson, J. H., \& Jackson, J. B. (2010). The relationship between coming to terms with family-of-origin difficulties and adult relationship satisfaction. The American Journal of Family Therapy, 38(3), $207-217$.

McKinney, C., \& Renk, K. (2008a). Differential parenting between mothers and fathers: Implications for late adolescents. Journal of Family Issues, 29(6), 806-827.

Nova-Kaltsouni, C. (1995). Socialization, the birth of the social subject. Athens: Gutenberg.

Pappa, B. (2006). Parental as profession: Psychological types of parents and behavior of children and adolescents. Athens: Kastanioti Publishing.

Phares, V., Fields, S., \& Kamboukos, D. (2009). Fathers' and mothers' involvement with their adolescents. Journal of Child and Family Studies, 18(1), 1-9.

Radziszewska, B., Richardson, J. L., Dent, C. W., \& Flay, B. R. (1996). Parenting style and adolescent depressive symptoms, smoking, and academic achievement: Ethnic, gender, and SES differences. Journal of Behavioural Medicine, 19(3), $289-305$.

Ren, L., \& Pope Edwards, C. (2015). Pathways of influence: Chinese parents' expectations, parenting styles, and child social competence. Early Child Development and Care, 185(4), 614-630. 
Rhein, L. M., Ginsburg, K. R., Schwarz, D. F., Pinto-Martin, J. A., Zhao, H., Morgan, A. P., \& Slap, G. B. (1997). Teen father participation in child rearing: Family perspectives. Journal of Adolescent Health, 21(4), 244-252.

Ryan, R. M., Tolani, N., \& Brooks-Gunn, J. (2009). Relationship trajectories, parenting stress, and unwed mothers' transition to a new baby. Parenting-Science and Practice, 9(1-2), 160-177.

Sang, M. L., Daniels, M. H., \& Kissinger, D. B. (2006). Parental influences on adolescent adjustment: Parenting styles versus parenting practices. Family Journal, 14, 253-259.

Stewart-Brown, S. (2008). Improving parenting: The why and the how. Archives of Disease in Childhood, 93(2), 102-104.

Strauss, M. A., \& Stewart, J. H. (1999). Corporal punishment by American parents: National data on prevalence, chronicity, severity and duration in relation to child and family characteristics. Child and Family Psychology Review, 2(2), 55-70.

Temiz, G. (2020). The relationship between mothers' psychological well-being and their attitudes towards their children. Psychology, 10(1), 1-9.

Uji, M., Sakamoto, A., Adachi, K., \& Kitamura, T. (2014). The impact of authoritative, authoritarian, and permissive parenting styles on children's later mental health in Japan: Focusing on parent and child gender. Journal of Child and Family Studies, 23(2), 293-302.

Vander, J. (1993). Human development. New York: McGraw-Hill.

Vlachogianni, A., \& Aggeli K. (2014). Parental role enhancement programs. Cognitive-Behavioural Research \& Therapy, 1(1), 41-53.

Wayland, J., \& Rawlins, R. (1997). African American teen mothers' perceptions of parenting. Journal of Pediatric Nursing, 12(1), 13-20.

Whitfield, C. L. (1987). Healing the child within: Discovery and recovery for adult children of dysfunctional families. Deerfield Beach, FL: Health Communications. 